\title{
Near work, outdoor activity, and myopia in children in rural China: the Handan offspring myopia study
}

\author{
Zhong Lin', Tie Ying Gao ${ }^{2}$, Balamurali Vasudevan ${ }^{3}$, Kenneth J. Ciuffreda ${ }^{4}$, Yuan Bo Liang ${ }^{1,8^{*}}$, Vishal Jhanji, ${ }^{5,6}$, \\ Su Jie Fan², Wei Han² and Ning Li Wang ${ }^{7}$
}

\begin{abstract}
Background: The near work and outdoor activity are the most important environmental risk factors for myopia. However, data from Chinese rural children are relatively rare and remain controversial. Therefore, the purpose of this study was to evaluate the relationship of both near work and outdoor activities with refractive error in rural children in China.

Methods: In this cross-sectional study, 572 (65.1\%) of 878 children (6-18 years of age) were included from the Handan Offspring Myopia Study (HOMS). Information from the parents on these children, as well as the parent's non-cycloplegic refraction, were obtained from the database of the Handan Eye Study conducted in the years 2006-2007. A comprehensive vision examination, including cycloplegic refraction, and a related questionnaire, were assessed on all children.

Results: The overall time spent on near work and outdoor activity in the children was $4.8 \pm 1.6$ and $2.9 \pm 1.4 \mathrm{~h}$ per day, respectively. Myopic children spent more time on near work ( $5.0 \pm 1.7 \mathrm{~h}$ vs.4.7 $\pm 1.6 \mathrm{~h}, p=0.049)$, while no significant difference was found in outdoor activity hours (2.8 $\pm 1.3 \mathrm{~h}$ vs. $3.0 \pm 1.4 \mathrm{~h}, p=0.38$ ), as compared to non-myopic children. In the multiple logistic analysis, in general, no association between near work and myopia was found after adjusting for the children's age, gender, parental refractive error, parental educational level, and daily outdoor activity hours [odds ratio (OR), 95\% confidence interval (Cl): 1.10, 0.94-1.27]. However, a weak protective effect of the outdoor activity on myopia was found (OR, 95\% Cl: 0.82, 0.70-0.96), after adjusting for similar confounders.
\end{abstract}

Conclusions: In general, no association between near work and myopia was found, except for the high near work subgroup with moderate outdoor activity levels. A weak protective effect of outdoor activity on myopia in Chinese rural children was observed.

Keywords: near work, outdoor activity, myopia, rural

\section{Background}

Myopia is a common vision disorder. The prevalence of myopia in Chinese children living in China [1] was reported to be higher compared to children from Nepal, [2,3] India, [4, 5] Singapore, [6, 7] Africa, [8] Chile, [9] Australia, [10, 11] the United States, [12] and England [13, 14].

Cross-sectional and longitudinal studies on Chinese urban children have found an association between near work/outdoor activity and myopia/myopic progression.

\footnotetext{
* Correspondence: yuanboliang@126.com

'The Eye Hospital, School of Ophthalmology and Optometry, Wenzhou Medical University, No. 270 West College Road, Wenzhou, Zhejiang 325027, China ${ }^{8}$ Centre for Public Health, School of Medicine, Dentistry and Biomedical Sciences, Queen's University, Belfast, UK

Full list of author information is available at the end of the article
}

[15-24] Regarding Chinese rural children, Lu et al. [25] reported no association between either outdoor activity or near work with myopia in the Xichang Pediatric Refractive Error Study (X-PRES) in southern rural China. In contrast, $\mathrm{Wu}$ et al. reported that more frequent outdoor activity was associated with a lower prevalence of myopia in Taiwanese rural Chinese primary school children [26]. Interestingly, data from Chinese rural children are relatively rare and remain controversial.

Therefore, we conducted the Handan Offspring Myopia Study (HOMS), which aimed to assess the relationship between near work/outdoor activity and myopia in a rural population in northern China. 


\section{Methods}

The HOMS, an offspring study of the Handan Eye Study (HES), primarily aimed to investigate the familial associations for myopia among parents and their offspring aged 6 to 18 years in rural northern China, as well as to assess the myopic shift between the two generations and its putative risk factors [27]. Subjects were drawn from the HOMS, which is a part of the offspring of HES [28]. The study design, procedures, and characteristics of HOMS are reported elsewhere [27]. In brief, the study was undertaken in a rural population in Yongnian County, Handan, which is located in southern Hebei province (about $500 \mathrm{~km}$ south of Beijing). This geographic area has demographic characteristics similar to other rural regions of China according to the 2000 National Census [28]. Thirteen villages were randomly selected for the HES. Among them, 6 villages with age of parents more than 30 years were selected for the HOMS. From March to June in 2010, 878 of 1238 children eligible for the HOMS (70.9\% response rate), aged 6 to 18 years, were examined in the HOMS. There were 462 boys $(52.6 \%)$ and 416 girls (47.4\%), aged $10.4 \pm 2.4$ and $10.8 \pm 2.6$ years, respectively. All participants were self-identified Han people. In contrast to the non-participants, children who participated were more likely to be boys, younger, and studying or working near the villages. Information relating to the parents was obtained from the HES.

This study adhered to the Declaration of Helsinki. Written, informed consent was obtained from at least one parent/guardian. Ethics Committee approval was obtained from the Handan Eye Hospital.

\section{Questionnaire}

Each participant completed a standard, myopia-based questionnaire in a face-to-face interview by a trained staff member conducted in the local dialect of the study site. This questionnaire was used in the Sydney Myopia Study, and it was slightly modified and translated into Chinese $[18,20,29]$. The interview covered a broad range of questions regarding various daily activities. These activities were classified into near work, midworking distance, and outdoor activities. Near work activities were defined as those having less than a $50 \mathrm{~cm}$ working distance, including drawing pictures, doing homework, reading books, attending additional classes, and using handheld computers. Activities at the midworking distance included watching television, playing video games and using computers. Outdoor activities included leisure time spent outside (e.g., staying in the backyard, walking, riding a bike/scooter, going shopping) and outdoor sports (e.g., running, playing ball, skipping rope). Activity levels were graded as low, moderate, and high using population tertiles of the average daily hours spent on these different activities.

\section{Cycloplegic refraction}

Refraction was performed using an autorefractor (model KR8800, Topcon, Tokyo, Japan) before and after cycloplegia in the children. Cycloplegic autorefraction was performed 20 min after instilling 3 drops of cyclopentolate 1\% (Cyclogyl, Alcon).Three readings were obtained in each eye, and the average was recorded. A fully dilated pupil was defined as one with a diameter of $\geq 6 \mathrm{~mm}$ and having absence of any pupillary light reflex.

Information relating to the parents was obtained from the HES database including non-cycloplegic autorefracion. All examinations were performed using the same protocols and equipment as the HES [30].

\section{Data analysis and definitions}

No imputations were done for the missing data. Only data from the right eye were used, since there was a high correlation in spherical equivalent (SE) between the right and left eye $\left(r_{\text {pearson }}=0.94, p<0.001\right)$. Data were analyzed using commercial software (SAS ver. 9.1.3; SAS Institute, Cary, NC) with the significance level set at less than 0.05 .

The SE was calculated as the sphere $+1 / 2$ cylinder. Myopia, emmetropia, and hyperopia were defined as SE $<-0.5$ diopters $(\mathrm{D}),-0.5 \mathrm{D} \leq \mathrm{SE} \leq 0.5 \mathrm{D}$, and $\mathrm{SE}>0.5 \mathrm{D}$, respectively $[27,30]$. Average parental refractive error was defined as the combined average of the non-cycloplegic SE of the father and mother. Average daily hours of activities were presented as the mean \pm standard deviation. The daily hours of activities were calculated using the formula: [(average hours spend on weekday) $\times 5+$ (average hours spend on weekends) $\times 2$ )]/7. Diopter-hours were calculated using a cumulative near work exposure variable at the near and midworking distances using the formula: $3 \times$ (reading for pleasure hours +study hours) + $2 \times$ (computer hours + video games hours) + watching television hours $[18,20]$. Activity level was first analyzed continuously as the average daily hours, and then by tertile activity groups. Generalized estimating equations (GEEs) were used to assess the association between the $\mathrm{SE}$ and daily activity/confounders (fixed effects), as well as considering the children from the same family (family effect) as a random effect. Parental educational level was categorized as the following: illiterate, primary school, junior high school, and senior high school and above. The joint effect of near work and outdoor activities, as well as family effect, using stepwise logistic regression models was performed after adjusting for the different risk factors using GEEs. Odds ratios (OR) and 95\% confidence intervals (CIs) are presented.

\section{Results}

A total of 878 (70.9\%) of 1238 children aged 6 to 18 years participated in this study. Of these, 598 with completed cycloplegic autorefraction, myopia questionnaire, and 
parental refractive information were included. Overall, 13 children with either amblyopia or strabismus, 1 child with previous corneal surgery, and 12 children's parents with either amblyopia or strabismus were excluded. Hence, 572 (65.1\%) of 878 children were included in the final analysis. There were 170, 132, 42, and 3 families with one, two, three, and four child(ren). No significant difference was found for the children's age, prevalence of myopia, and SE between the included and excluded children $(p=0.44, p=0.65$, and $p=0.63$, respectively). However, there were more boys in the included children as compared to the excluded children $(p=0.03)$ (Table 1$)$. Fig. 1 presents the distribution of refractive error in children $6-11$ years old and $12-17$ years old.

Children spent $4.8 \pm 1.6$ and $2.9 \pm 1.4 \mathrm{~h}$ per day on near work and outdoor activity, respectively. Regarding the daily near work time in hours, boys and myopic children spent significantly more time on near work than either girls ( $4.9 \pm 1.7$ vs. $4.6 \pm 1.5, p=0.042)$ or non-myopic children (5.0 \pm 1.7 vs. $4.7 \pm 1.6, p=0.049)$, respectively. Although there were significant differences among the paternal educational levels for near work time $(p=0.018)$, no significant differences were found in the subsequent pair-wise comparisons. No significant differences were found among the other groups, e.g., number of myopic parents, maternal educational levels (Table 2). Regarding the daily outdoor activity time, only a borderline difference was found among the maternal education levels ( $p=$ 0.054). No significant differences were found among the other groups for outdoor activity. The daily hours spent on mid-work distance activities were also not associated with the mean SE ( $\left.r_{\text {spearman }}=-0.003, p=0.94\right)$.

Table 3 and Table 4 present the mean SE of the children and their associations with daily activity hours, after being divided into tertile groups among the different subgroups. A high myopic refractive error was found in the fathers with the primary school education level

Table 1 Characteristics of the included and excluded children

\begin{tabular}{llll}
\hline & $\begin{array}{l}\text { Included } \\
(N=572)\end{array}$ & $\begin{array}{l}\text { Excluded } \\
(N=306)\end{array}$ & $P$ \\
\hline Age (years) & $10.6 \pm 2.5$ & $10.5 \pm 2.5$ & 0.44 \\
Gender (boys:girls) & $316: 256$ & $146: 160$ & 0.03 \\
$\begin{array}{l}\text { Prevalence of myopia (\%) } \\
\text { a }\end{array}$ & & & \\
Boys & 17.1 & 17.2 & 0.86 \\
Girls & 32.8 & 27.3 & 0.12 \\
Total & 24.1 & 22.6 & 0.65 \\
Spherical equivalent (D) ${ }^{\text {a }}$ & & & \\
$\quad$ Boys & $0.15 \pm 1.18$ & $0.19 \pm 1.44$ & 0.81 \\
Girls & $-0.17 \pm 1.27$ & $-0.24 \pm 1.75$ & 0.65 \\
$\quad$ Total & $0.01 \pm 1.23$ & $-0.05 \pm 1.63$ & 0.63 \\
${ }^{2}$ Refractive error data were missing in 24 boys and 17 girls in the excluded group
\end{tabular}

subgroup if their children spent more time on near work $(p=0.01)$. The combined effects of outdoor and near work activities on the odds for myopia are presented in Fig. 2. Children with a high level of outdoor activity and low level of near work were used as the reference group (OR 1.0). Children with moderate outdoor activity and high near work had higher odds for myopia than the reference group (OR, 2.16; 95\% CI, 0.69-6.77). However, none of the other subgroups had significant odds for myopia compared to the reference group (Fig. 2).

Stepwise multiple logistic models were used to analyze the correlation between daily near work/ outdoor activity hours and myopia (Table 5). In a univariate model, children who spent more time on near work were 1.12 (95\% CI 1.01-1.25) times more likely to be myopic. However, no significant association between daily near work hours and myopia was found after adjusting for confounders, such as the children's age, gender, average parental refractive error, parental education level, and daily outdoor activity hours. Outdoor activity had no protective effect for myopia (OR, 0.93; 95\% CI, 0.82-1.07) in the univariate model. However, after adjusting for children's age, gender, average parental refractive error, parental education level, and daily near work hours, outdoor activity showed a weak protective effect for myopia (OR, 0.82; 95\% CI, 0.70-0.96).

\section{Discussion}

Although cross-sectional and longitudinal studies on Chinese urban children have found an association between near work/outdoor activity and myopia/myopic progression, [15-20] studies related to the association of near work and outdoor activity with myopia are rare and equivocal among Chinese rural children [24]. In Taiwan, $\mathrm{Wu}$ et al. reported that more frequent outdoor activity was associated with a lower prevalence of myopia in rural Chinese primary school children $[16,26]$. In contrast, in the Strabismus, Amblyopia and Refractive Error Study (STARS) in Singaporean preschool Chinese children, and in the X-PRES in Chinese rural teenagers, negative results were reported related to both near work and outdoor activity [25, 31]. A meta-analysis that included 7 cross-sectional studies (including STARS and $\mathrm{X}$-PRES) have reported that one additional hour per week spent outdoors would reduce the odds by $2 \%$ (odds ratio, 95\% confidence interval: $0.98,0.97-0.99$ ) of having myopia in children and adolescents.

The current study performed in Handan reports the effect and possible interaction of near work and outdoor activity on myopia in a wide age range among the Chinese rural population. In the present study, the parental refractive error, one of the important confounding factors for children's myopia, [31,32] was obtained directly. We found that myopic children spent more time on near work compared to non-myopic children. However, in general, the daily near 


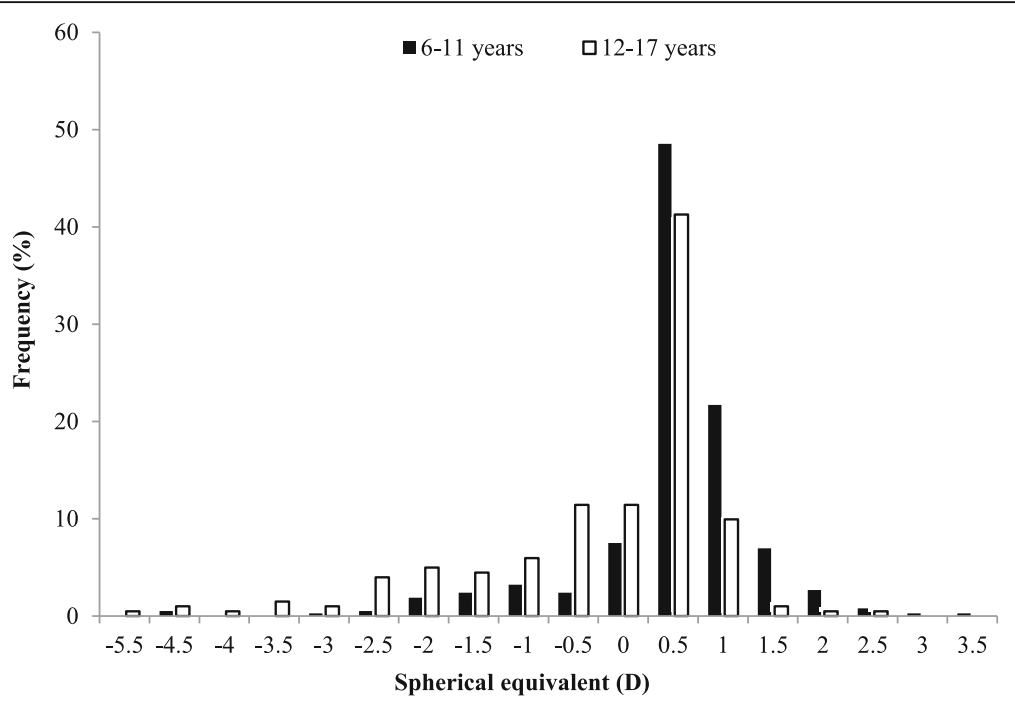

Fig. 1 Distribution of refractive error in children 6-11 years old and 12-17 years old

Table 2 Near work and outdoor activity time (hours per day) in Handan Offspring Myopia Study children

\begin{tabular}{|c|c|c|c|c|c|}
\hline & \multirow[t]{2}{*}{$\mathrm{N}$} & \multicolumn{2}{|l|}{ Near work } & \multicolumn{2}{|l|}{ Outdoor } \\
\hline & & Mean \pm SD & $p$ value & Mean \pm SD & $p$ value \\
\hline \multicolumn{6}{|l|}{ Gender } \\
\hline Boys & 316 & $4.9 \pm 1.7$ & $0.042^{\mathrm{a}}$ & $3.0 \pm 1.4$ & $0.12^{a}$ \\
\hline Girls & 256 & $4.6 \pm 1.5$ & & $2.8 \pm 1.4$ & \\
\hline \multicolumn{6}{|l|}{ Refractive Status } \\
\hline Myopia & 138 & $5.0 \pm 1.7$ & $0.049^{a}$ & $2.9 \pm 1.3$ & $0.38^{\mathrm{a}}$ \\
\hline No myopia & 434 & $4.7 \pm 1.6$ & & $3.0 \pm 1.4$ & \\
\hline \multicolumn{6}{|l|}{ Number of myopic parents } \\
\hline None & 197 & $4.6 \pm 1.7$ & $0.32^{b}$ & $2.9 \pm 1.3$ & $0.74^{\mathrm{b}}$ \\
\hline Either & 272 & $4.9 \pm 1.7$ & & $2.9 \pm 1.4$ & \\
\hline Both & 103 & $4.7 \pm 1.4$ & & $3.0 \pm 1.5$ & \\
\hline \multicolumn{6}{|l|}{ Maternal education levels } \\
\hline Illiteracy & 87 & $4.7 \pm 1.6$ & $0.17^{\mathrm{b}}$ & $2.9 \pm 1.2$ & $0.054^{\mathrm{b}}$ \\
\hline Primary school & 279 & $4.6 \pm 1.7$ & & $2.8 \pm 1.3$ & \\
\hline Junior high school & 189 & $5.0 \pm 1.5$ & & $3.2 \pm 1.6$ & \\
\hline Senior high school and above & 17 & $4.8 \pm 1.6$ & & $3.1 \pm 1.4$ & \\
\hline \multicolumn{6}{|l|}{ Paternal education levels } \\
\hline Illiteracy & 21 & $5.4 \pm 2.5$ & $0.018^{b}$ & $3.0 \pm 1.1$ & $0.38^{\mathrm{b}}$ \\
\hline Primary school & 166 & $4.6 \pm 1.6$ & & $2.8 \pm 1.4$ & \\
\hline Junior high school & 343 & $4.7 \pm 1.5$ & & $3.0 \pm 1.5$ & \\
\hline Senior high school and above & 42 & $5.3 \pm 2.1$ & & $2.8 \pm 1.3$ & \\
\hline Total & 572 & $4.8 \pm 1.6$ & & $2.9 \pm 1.4$ & \\
\hline
\end{tabular}

at-test

${ }^{\mathrm{b}}$ generalized linear models 
Table 3 Mean spherical equivalent (diopter) ${ }^{a}$ as a function of near work activity (tertiles of hours per day)

\begin{tabular}{|c|c|c|c|c|}
\hline Near work activity (hours per day) ${ }^{b}$ & $\begin{array}{l}\text { Low }(0 \sim 4.0) \\
N=185\end{array}$ & $\begin{array}{l}\text { Moderate }(4.0 \sim 5.1) \\
N=196\end{array}$ & $\begin{array}{l}\text { High }(>5.1) \\
N=191\end{array}$ & $P$ value \\
\hline \multicolumn{5}{|l|}{ Gender } \\
\hline Boys & 0.33 & 0.08 & 0.06 & 0.17 \\
\hline Girls & -0.15 & -0.19 & -0.20 & 0.96 \\
\hline \multicolumn{5}{|l|}{ Refractive Status } \\
\hline Myopia & -1.73 & -1.74 & -1.80 & 0.95 \\
\hline No myopia & 0.63 & 0.52 & 0.53 & 0.25 \\
\hline \multicolumn{5}{|l|}{ Number of myopic parents } \\
\hline None & 0.09 & -0.04 & 0.04 & 0.80 \\
\hline Either & 0.30 & 0.04 & 0.01 & 0.17 \\
\hline Both & -0.29 & -0.32 & -0.46 & 0.89 \\
\hline \multicolumn{5}{|l|}{ Maternal education level } \\
\hline Illiteracy & 0.15 & 0.19 & 0.12 & 0.97 \\
\hline Primary school & -0.01 & -0.01 & 0.00 & 0.99 \\
\hline Junior high school & $0.39^{c}$ & -0.13 & -0.04 & 0.06 \\
\hline Senior high school and above & -1.30 & -0.68 & -0.85 & 0.88 \\
\hline \multicolumn{5}{|l|}{ Paternal education level } \\
\hline Illiteracy & 0.08 & 0.27 & 0.53 & 0.50 \\
\hline Primary school & $0.38^{c}$ & -0.11 & -0.15 & 0.01 \\
\hline Junior high school & -0.06 & -0.05 & 0.04 & 0.78 \\
\hline Senior high school and above & 0.11 & -0.01 & -0.61 & 0.50 \\
\hline Total & 0.10 & -0.04 & -0.06 & 0.35 \\
\hline
\end{tabular}

${ }^{a}$ Adjusted for children's age, gender, average parental refractive error, maternal and paternal education level, and outdoor activity time as fixed effects, and family effect as a random effect

${ }^{b}$ Includes drawing, homework, reading, and handheld computer use. Cut-off points were based on population tertiles for average daily hours spent at near 'Significant (Bonferroni test) compared with the highest tertile of activity as the reference group

work was not associated with the children's myopia as per the multiple logistic analysis, after adjusting for the children's age, gender, average parental refractive error, parental education level, and outdoor activity time. This was consistent with previous studies conducted in Caucasians, $[23,33,34]$ and East Asians, living in Sydney [23]. This was also consistent with findings in Singaporean preschool Chinese children in STARS, and in X-PRES in Chinese rural teenagers $[25,31]$. However, our results were different from those reported in Beijing urban students $[16,17,20]$.

A weak protective effect of outdoor activity for myopia was found in the present study. The association between more time outdoors and either a lower prevalence of myopia, or more hyperopic refractive error, was reported in Caucasians [23, 34, 35] as well as Singaporean teenagers [24]. Furthermore, this association was also found in the Chinese $[16,17,26]$. In Taiwan, Wu et al. reported that more frequent outdoor activity was associated with a lower prevalence of myopia (OR, 0.3; 95\% CI, 0.1-0.9) in rural Chinese school children aged 7-12 years [26]. Guo et al. also reported that less outdoor activity and more time spent indoors studying was associated with myopia progression and elongation of axial length in primary students in grades 1 and grade 4 in Beijing (age range: 5-13 years) [17]. However, the association was not found either in X-PRES in Chinese rural teenagers (mean age: 14.6 years) [25] or in another study involving Beijing urban school children (aged 6-17 years) [20]. It is noteworthy that the protective effect of outdoor activity in our study was not found after the children were divided into two groups by the age cut-off point of 12 (data not shown).

The inconsistent findings of the different studies in both Chinese urban and rural children may be attributed to the different living environments between rural and urban areas. Lin et al. reported the generational myopic shift was estimated to $1 \mathrm{D}$ more in Beijing urban area compared to that in Handan rural area [36, 37]. The less urbanized environment and more time outdoors were reported to be associated with lower prevalence of myopia [23, 35-37]. These may be attributed to more time spent outdoors in the sun by rural children $[23,38]$. Hence, the rural children are exposed to a less myopigenic living environment compared to their urban counterparts. 
Table 4 Mean spherical equivalent (diopter) as a function of outdoor activity (tertiles of hours per day)

\begin{tabular}{|c|c|c|c|c|}
\hline Outdoor activity (hours per day) & $\begin{array}{l}\text { Low }(0 \sim 2.3) \\
N=191\end{array}$ & $\begin{array}{l}\text { Moderate (2.3 3.2) } \\
N=187\end{array}$ & $\begin{array}{l}\text { High }(>3.2) \\
N=194\end{array}$ & $P$ value \\
\hline \multicolumn{5}{|l|}{ Gender } \\
\hline Boys & 0.05 & 0.10 & 0.27 & 0.32 \\
\hline Girls & -0.13 & -0.30 & -0.10 & 0.49 \\
\hline \multicolumn{5}{|l|}{ Refractive Status } \\
\hline Myopia & -1.69 & -1.76 & -1.84 & 0.82 \\
\hline No myopia & 0.54 & 0.53 & 0.61 & 0.52 \\
\hline \multicolumn{5}{|l|}{ Number of myopic parents } \\
\hline None & 0.03 & -0.19 & 0.25 & 0.10 \\
\hline Either & 0.08 & -0.01 & 0.26 & 0.24 \\
\hline Both & -0.53 & -0.09 & -0.46 & 0.32 \\
\hline \multicolumn{5}{|l|}{ Maternal education level } \\
\hline Illiteracy & 0.16 & -0.10 & 0.40 & 0.09 \\
\hline Primary school & -0.09 & -0.05 & 0.14 & 0.37 \\
\hline Junior high school & 0.01 & -0.07 & 0.11 & 0.68 \\
\hline Senior high school and above & 0.11 & -0.94 & -1.68 & 0.52 \\
\hline \multicolumn{5}{|l|}{ Paternal education level } \\
\hline Illiteracy & -0.01 & 0.22 & 0.54 & 0.62 \\
\hline Primary school & 0.07 & -0.11 & 0.22 & 0.30 \\
\hline Junior high school & -0.06 & -0.11 & 0.10 & 0.31 \\
\hline Senior high school and above & -0.27 & -0.12 & -0.25 & 0.97 \\
\hline Total & -0.04 & -0.09 & 0.12 & 0.20 \\
\hline
\end{tabular}

${ }^{2}$ Adjusted for children's age, gender, average parental refractive error, maternal and paternal education level, and near work time as fixed effects, and family effect as a random effect

${ }^{b}$ Includes outdoor sports, playing out of doors, and other outdoor leisure activities. Cut-off points were based on population tertiles for average daily hours spent outside

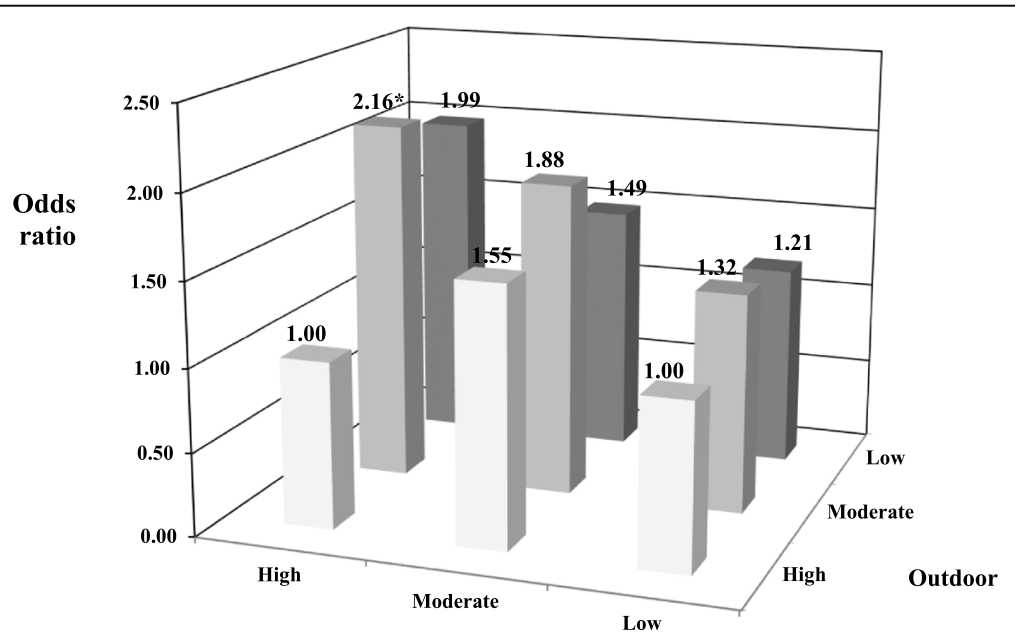

Near work

Fig. 2 Multivariable-adjusted odds ratios (adjusted for children's age, gender, average parental refractive error, maternal and paternal education level) for myopia by reported average daily hours spent on near work versus outdoor activities. Activities were divided into tertiles of high, moderate, and low levels of activity. The group with high levels of outdoor activity and low levels of near work is the reference group. The subgroup with high near work levels and moderate outdoor levels was significantly at risk for myopes (asterisk) 
Table 5 Stepwise logistic analysis of daily near work and outdoor activity hours for myopia

\begin{tabular}{llllll}
\hline & \multicolumn{2}{l}{ Near work } & & & \multicolumn{2}{l}{ Outdoor } \\
\cline { 2 - 3 } & OR & $95 \% \mathrm{Cl}$ & & OR & $95 \% \mathrm{Cl}$ \\
\hline Model 1 & 1.12 & $1.01-1.25$ & & 0.93 & $0.82-1.07$ \\
Model 2 & 1.07 & $0.94-1.21$ & & 0.86 & $0.74-1.00$ \\
Model 3 & 1.05 & $0.92-1.21$ & & 0.86 & $0.75-1.00$ \\
Model 4 & 1.10 & $0.94-1.27$ & & 0.82 & $0.70-0.96$ \\
\hline
\end{tabular}

Model 1 for near work: adjusted for near work time as a fixed effects, and family effect as a random effect; Model 1 for outdoor: adjusted for outdoor activity time as fixed effect, and family effect as a random effect

Model 2: model $1+$ children's age and gender

Model 3: model $2+$ average parental refractive error

Model 4 for near work: model $3+$ maternal and paternal education level, and outdoor activity time; Model 4 for outdoor: model $3+$ maternal and paternal education level, and near work time

There were some limitations in the present study. First, the population sample used was obtained from the offspring of the participants in the HES. Consequently, the sample size was relatively small. Second, the activities were self-reported by the children. Although this method was predominant in previously reported studies, the estimation of activity time could be subject to recall bias. However, we randomly reassessed 50 children who completed the questionnaire over a one-month period, and the weighted kappa value was acceptable (0.82) comparing the two questionnaires findings. Third, the information on activities of the children who did not respond (nearly $30 \%)$ was unknown.

In summary, in general, the association between near work and myopia was not found in this study. However, a very weak protective effect of outdoor activity on myopia in Chinese rural children was suggested. Further longitudinal studies are warranted.

\section{Conclusion}

In summary, in this sample of rural Chinese rural children, no association between near work and myopia was found, except for children with high near work and moderate outdoor activity load. Furthermore, a weak protective effect of outdoor activity on myopia in Chinese rural children was observed.

\section{Additional file}

Additional file 1: Dataset. (XLS $112 \mathrm{~kb}$ )

\section{Abbreviations}

Cl: Confidence interval; GEEs: Generalized estimating equations; HES: Handan eye study; HOMS: Handan offspring myopia study; OR: Odds ratio; STARS: Strabismus, amblyopia and refractive error study; X-PRES: Xichang pediatric refractive error study

\section{Acknowledgements}

The authors thank Dr. Lei Li, Dr. Peng Zhang and Dr. Qian Jia (Handan Eye Hospital), and Dr. Xiao Dong Yang (Nanjing Tongren Hospital), for their invaluable assistance in data collection.

\section{Funding}

The study was supported by the Key Technologies Research Development Program (No.1113108019) from the Bureau of Science and Technology of Handan City, Hebei Province, China, the Beijing Science \& Technology Novel Star Program (2009B44), and Zhejiang Health Innovation Talents Program 2016025.

Availability of data and materials

The dataset supporting the conclusion of this article is available in the Additional file 1

\section{Authors' contributions}

YBL and NLW designed the study protocol and conducted the study as a supervisor. ZL, TYG, and BV participated in the study design, conducted statistical analysis, and drafted the manuscript. KJC and VJ participated in the study design, and revised the manuscript. WH and SJF supervised and monitored the study implementation. All authors read and approved the final manuscript.

\section{Ethics approval and consent to participate}

The study followed the tenets of the Declaration of Helsinki and was approved by the Ethics Committee of the Handan Eye Hospital. Written, informed-consent of the parents was obtained.

\section{Consent for publication}

Written, informed-consent of the parents was obtained.

\section{Competing interests}

The authors declare that they have no competing interests.

\section{Publisher's Note}

Springer Nature remains neutral with regard to jurisdictional claims in published maps and institutional affiliations.

\section{Author details}

${ }^{1}$ The Eye Hospital, School of Ophthalmology and Optometry, Wenzhou Medical University, No. 270 West College Road, Wenzhou, Zhejiang 325027, China. ${ }^{2}$ Handan Eye Hospital, Handan, Hebei, China. ${ }^{3}$ College of Optometry, Mid Western University, Glendale, AZ, USA. ${ }^{4}$ Department of Biological and Vision Sciences, SUNY College of Optometry, New York, NY, USA. ${ }^{5}$ Department of Ophthalmology, University of Pittsburgh School of Medicine, Pittsburgh, PA, USA. ${ }^{6}$ Department of Ophthalmology and Visual Sciences, The Chinese University of Hong Kong, Hong Kong, China. ${ }^{7}$ Beijing Tongren Eye Center, Beijing Tongren Hospital, Capital Medical University, Beijing, China. ${ }^{8}$ Centre for Public Health, School of Medicine, Dentistry and Biomedical Sciences, Queen's University, Belfast, UK.

Received: 19 October 2016 Accepted: 7 November 2017 Published online: 17 November 2017

\section{References}

1. He M, Zeng J, Liu Y, Xu J, Pokharel GP, Ellwein LB. Refractive error and visual impairment in urban children in southern china. Invest Ophthalmol Vis Sci. 2004:45(3):793-9.

2. Sapkota YD, Adhikari BN, Pokharel GP, Poudyal BK, Ellwein LB. The prevalence of visual impairment in school children of upper-middle socioeconomic status in Kathmandu. Ophthalmic Epidemiol. 2008;15(1):17-23.

3. Pokharel GP, Negrel AD, Munoz SR, Ellwein LB. Refractive error study in children: results from Mechi zone. Nepal Am J Ophthalmol. 2000;129(4): 436-44.

4. Dandona R, Dandona L, Srinivas M, Sahare P, Narsaiah S, Munoz SR, Pokharel GP, Ellwein LB. Refractive error in children in a rural population in India. Invest Ophthalmol Vis Sci. 2002;43(3):615-22.

5. Murthy GV, Gupta SK, Ellwein LB, Munoz SR, Pokharel GP, Sanga L, Bachani D. Refractive error in children in an urban population in New Delhi. Invest Ophthalmol Vis Sci. 2002;43(3):623-31. 
6. Saw SM, Carkeet A, Chia KS, Stone RA, Tan DT. Component dependent risk factors for ocular parameters in Singapore Chinese children. Ophthalmology. 2002;109(11):2065-71.

7. Dirani M, Chan YH, Gazzard G, Hornbeak DM, Leo SW, Selvaraj P, Zhou B, Young $T L$, Mitchell $P$, Varma $R$, et al. Prevalence of refractive error in Singaporean Chinese children: the strabismus, amblyopia, and refractive error in young Singaporean children (STARS) study. Invest Ophthalmol Vis Sci. 2010;51(3):1348-55.

8. Naidoo KS, Raghunandan A, Mashige KP, Govender P, Holden BA, Pokharel GP, Ellwein LB. Refractive error and visual impairment in African children in South Africa. Invest Ophthalmol Vis Sci. 2003:44(9):3764-70.

9. Maul E, Barroso S, Munoz SR, Sperduto RD, Ellwein LB. Refractive error study in children: results from La Florida. Chile Am J Ophthalmol. 2000;129(4):445-54.

10. Ip JM, Huynh SC, Robaei D, Kifley A, Rose KA, Morgan IG, Wang JJ, Mitchell P. Ethnic differences in refraction and ocular biometry in a population-based sample of 11-15-year-old Australian children. Eye (Lond). 2008;22(5):649-56.

11. Ojaimi E, Rose KA, Morgan IG, Smith W, Martin FJ, Kifley A, Robaei D, Mitchell P. Distribution of ocular biometric parameters and refraction in a population-based study of Australian children. Invest Ophthalmol Vis Sci. 2005;46(8):2748-54.

12. Kleinstein RN, Jones LA, Hullett S, Kwon S, Lee RJ, Friedman NE, Manny RE, Mutti DO, Yu JA, Zadnik K. Refractive error and ethnicity in children. Arch Ophthalmol. 2003;121(8):1141-7.

13. Logan NS, Shah P, Rudnicka AR, Gilmartin B, Owen CG. Childhood ethnic differences in ametropia and ocular biometry: the Aston eye study. Ophthalmic Physiol Opt. 2011;31(5):550-8.

14. Rudnicka AR, Owen CG, Nightingale CM, Cook DG, Whincup PH. Ethnic differences in the prevalence of myopia and ocular biometry in 10- and 11year-old children: the child heart and health study in England (CHASE). Invest Ophthalmol Vis Sci. 2010:51(12):6270-6.

15. Saw SM, Hong RZ, Zhang MZ, Fu ZF, Ye M, Tan D, Chew SJ. Near-work activity and myopia in rural and urban schoolchildren in China. J Pediatr Ophthalmol Strabismus. 2001;38(3):149-55

16. Guo Y, Liu L, Xu L, LV YY, Tang P, Feng Y, Meng M, Jonas JB. Outdoor activity and myopia among primary students in rural and urban regions of Beijing. Ophthalmology. 2013;120(2):277-83.

17. Guo Y, Liu $\sqcup$, Xu L, Tang $P$, LV YY, Feng Y, Meng M, Jonas JB. Myopic shift and outdoor activity among primary school children: one-year follow-up study in Beijing. PLoS One. 2013;8(9):e75260.

18. Lin Z, Vasudevan B, Jhanji V, Mao GY, Gao TY, Wang FH, Rong SS, Ciuffreda KJ, Liang YB. Near work, outdoor activity, and their association with refractive error. Optom Vis Sci. 2014;91(4):376-82.

19. Li SM, Li SY, Kang MT, Zhou Y, Liu LR, Li H, Wang YP, Zhan SY, Gopinath B, Mitchell $P$, et al. Near work related parameters and myopia in Chinese children: the Anyang childhood eye study. PLoS One. 2015;10(8):e0134514.

20. Lin Z, Vasudevan B, Mao GY, Ciuffreda KJ, Jhanji V, Li XX, Zhou HJ, Wang NL, Liang YB. The influence of near work on myopic refractive change in urban students in Beijing: a three-year follow-up report. Graefes Arch Clin Exp Ophthalmol. 2016:254(11):2247-55.

21. Mutti DO, Mitchell GL, Moeschberger ML, Jones LA, Zadnik K. Parental myopia, near work, school achievement, and children's refractive error. Invest Ophthalmol Vis Sci. 2002;43(12):3633-40.

22. Jones LA, Sinnott LT, Mutti DO, Mitchell GL, Moeschberger ML, Zadnik K Parental history of myopia, sports and outdoor activities, and future myopia. Invest Ophthalmol Vis Sci. 2007:48(8):3524-32.

23. Rose KA, Morgan IG, Ip J, Kifley A, Huynh S, Smith W, Mitchell P. Outdoor activity reduces the prevalence of myopia in children. Ophthalmology. 2008; 115(8):1279-85.

24. Dirani M, Tong L, Gazzard G, Zhang X, Chia A, Young TL, Rose KA, Mitchell $P$, Saw SM. Outdoor activity and myopia in Singapore teenage children. Br J Ophthalmol. 2009;93(8):997-1000.

25. Lu B, Congdon N, Liu X, Choi K, Lam DS, Zhang M, Zheng M, Zhou Z, Li L, Sharma A, et al. Associations between near work, outdoor activity, and myopia among adolescent students in rural China: the Xichang pediatric refractive error study report no. 2. Arch Ophthalmol. 2009;127(6):769-75.

26. Wu PC, Tsai $\mathrm{CL}, \mathrm{Hu}$ CH, Yang YH. Effects of outdoor activities on myopia among rural school children in Taiwan. Ophthalmic Epidemiol. 2010;17(5):338-42.

27. Gao TY, Zhang P, Li L, Lin Z, Jhanji V, Peng Y, Li ZW, Sun LP, Han W, Wang $\mathrm{NL}$, et al. Rationale, design, and demographic characteristics of the handan offspring myopia study. Ophthalmic Epidemiol. 2014;21(2):124-32.
28. Liang YB, Friedman DS, Wong TY, Wang FH, Duan XR, Yang XH, Zhou Q, Tao Q, Zhan SY, Sun LP, et al. Rationale, design, methodology, and baseline data of a population-based study in rural China: the Handan eye study. Ophthalmic Epidemiol. 2009;16(2):115-27.

29. Ojaimi E, Rose KA, Smith W, Morgan IG, Martin FJ, Mitchell P. Methods for a population-based study of myopia and other eye conditions in school children: the Sydney myopia study. Ophthalmic Epidemiol. 2005;12(1):59-69.

30. Liang YB, Wong TY, Sun LP, Tao QS, Wang JJ, Yang XH, Xiong Y, Wang NL, Friedman DS. Refractive errors in a rural Chinese adult population the Handan eye study. Ophthalmology. 2009;116(11):2119-27.

31. Low W, Dirani M, Gazzard G, Chan YH, Zhou HJ, Selvaraj P, Au Eong KG, Young TL, Mitchell P, Wong TY, et al. Family history, near work, outdoor activity, and myopia in Singapore Chinese preschool children. $\mathrm{Br}$ Ophthalmol. 2010;94(8):1012-6.

32. Jones-Jordan LA, Sinnott LT, Manny RE, Cotter SA, Kleinstein RN, Mutti DO, Twelker JD, Zadnik K. Early childhood refractive error and parental history of myopia as predictors of myopia. Invest Ophthalmol Vis Sci. 2010;51(1):115-21.

33. Ip JM, Saw SM, Rose KA, Morgan IG, Kifley A, Wang JJ, Mitchell P. Role of near work in myopia: findings in a sample of Australian school children. Invest Ophthalmol Vis Sci. 2008;49(7):2903-10.

34. Jones-Jordan LA, Mitchell GL, Cotter SA, Kleinstein RN, Manny RE, Mutti DO, Twelker JD, Sims JR, Zadnik K. Visual activity before and after the onset of juvenile myopia. Invest Ophthalmol Vis Sci. 2011;52(3):1841-50.

35. Guggenheim JA, Northstone K, McMahon G, Ness AR, Deere K, Mattocks C, Pourcain BS, Williams C. Time outdoors and physical activity as predictors of incident myopia in childhood: a prospective cohort study. Invest Ophthalmol Vis Sci. 2012;53(6):2856-65

36. Liang YB, Lin Z, Vasudevan B, Jhanji V, Young A, Gao TY, Rong SS, Wang NL, Ciuffreda KJ. Generational difference of refractive error in the baseline study of the Beijing myopia progression study. Br J Ophthalmol. 2013;97(6):765-9.

37. Lin Z, Gao TY, Vasudevan B, Jhanji V, Ciuffreda KJ, Zhang P, Li L, Mao GY, Wang NL, Liang YB. Generational difference of refractive error and risk factors in the handan offspring myopia study. Invest Ophthalmol Vis Sci. 2014;55(9):5711-7

38. McCarthy CS, Megaw P, Devadas M, Morgan IG. Dopaminergic agents affect the ability of brief periods of normal vision to prevent form-deprivation myopia. Exp Eye Res. 2007:84(1):100-7.

\section{Submit your next manuscript to BioMed Central and we will help you at every step:}

- We accept pre-submission inquiries

- Our selector tool helps you to find the most relevant journal

- We provide round the clock customer support

- Convenient online submission

- Thorough peer review

- Inclusion in PubMed and all major indexing services

- Maximum visibility for your research

Submit your manuscript at www.biomedcentral.com/submit
) Biomed Central 